\title{
Optimization Design and Reliability Analysis of Salix Cutting Tools based on Finite Element Method
}

\author{
Zhigang Liu ${ }^{\mathrm{a}, *}$, Zhongxiang Ma ${ }^{\mathrm{a}}$, Gengjin Sui ${ }^{\mathrm{a}}$, Dejian Zou ${ }^{\mathrm{b}}$, Zhen $\mathrm{Ji}^{\mathrm{a}}$, \\ and Guoliang $\mathrm{Li}^{\mathrm{a}}$ \\ ${ }^{a}$ College of Mechanical Engineering, Inner Mongolia University of Technology, Hohhot, 010051, China \\ ${ }^{b}$ School of Mechanical Engineering, Dalian University of Technology, Dalian, 116024, China
}

\begin{abstract}
Slight vibrations in the reciprocating brush cutter blade reciprocating motion will seriously affect crop quality problems. A method of application of topology optimization theory for the stubble cutter method was put forward in this paper. Firstly, the finite element software ABQUS was used to simulate the stubble of Salix psammophila, and the stress of the blade during the stubble was obtained according to the stubble blade during the stress conditions of topology optimization. According to the comparison of the simulation cutting conditions before and after double-action cutting, the stress is more uniform after optimization, the maximum force is reduced, and the stubble effect is obviously improved. Through theoretical analysis and cutting test analysis of tool life after topology optimization, it was found that the topology optimized double-action knife is improved and has a longer life expectancy. This study provides the basis for the development of reciprocating shrub stubble blades.
\end{abstract}

Keywords: finite element; Salix; simulation cutting; double action knife; topology optimization; reliability

(Submitted on November 15, 2018; Revised on December 11, 2018; Accepted on January 8, 2019)

(C) 2019 Totem Publisher, Inc. All rights reserved.

\section{Introduction}

Salix is the typical representative of windbreak and sand control in northwest and north China. Its various uses as biomass energy and cash crops have made the current research and development on the rejuvenation process and cutting equipment of Salix stumps a top priority [1]. China's cutting equipment includes the following categories. For example, it is widely used in reciprocating cutters in agricultural and forestry harvesting machines [2], disc rotary cutters in whole-stalk harvesting machines [3], and recirculating cutters for harvesting grass crops and pastures [4].

Regardless of the type of model, the flat file is the core part of the flat twister. The reciprocating inertial force and some unbalanced centrifugal inertia force will produce double-action knife slightly vibration, and prolonged slight vibration can lead to double-action knife wear. This reduces stubble quality (stubble, tear, etc.), thereby reducing the rate of Salix germination in the coming year [5]. At present, Chen researched the influence of the sliding angle of the reciprocating shredding cutter on the cutting force [6]. Song studied the effect of the optimized reciprocating cutter blade on the cutting work of cotton stalk [7]. Until now, there have not been studies on the relationship between double-acting knife cutting tools and the germination rate of Salix. Therefore, it is of great significance to study the flat stubble cutting tools of the shrub flat stubble machine.

In order to optimize the cutting tool of the reciprocating bush rake, it is necessary to analyze the force of the boring machine tool during the rake process. Therefore, the finite element method is used to simulate the cutting process of Salix. Through the process of iteration, the optimal structure is obtained. The OptiStruct software of Altair Company is used to optimize the double-action knife of Salix lawn harvester in order to reduce the stress during stubble and improve the stubble effect. According to the double blade life theory and physical test results, the reliability of the double-acting knives after topology optimization is analyzed.

* Corresponding author.

E-mail address: 1007940338@qq.com 


\section{Salix Cutting Mechanism}

\subsection{Salix Cutting Characteristics}

Desert shrub native biological material from a plant cell forms due to irregular texture, and the inner surface of the water evaporation rate varies. Anisotropy is exhibited in the mechanical and physical properties. The anisotropy of sandy shrubs determines the mechanical anisotropy such as elasticity, strength, and processing properties [8]. The cutting characteristics of anisotropic shrubs result in varied axial, radial, and tangential cutting of Salix. Figure 1 shows a schematic diagram of the cutting direction.

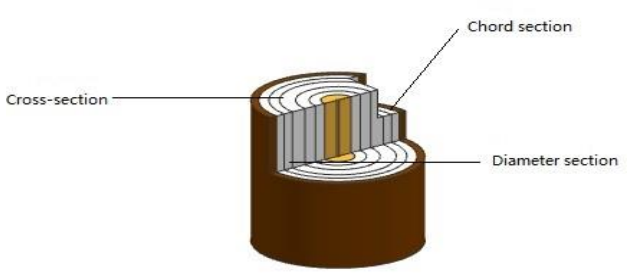

Figure 1. Salix cutting direction diagram

Salix as a mechanical property of the study has a crucial role in deepening the understanding of the cutting mechanism. The samples are from January 2017 in the Ordovician city Hunger Qi Kabuki desert. In accordance with national standards GB / T 1940-1991, the samples are measured using electrical measurements to determine the elastic parameters Salix, as shown in Table 1.

Table 1. Salix elasticity sheet unit: MPA

\begin{tabular}{ccccccccc}
\hline$E_{L}$ & $E_{R}$ & $E_{T}$ & $\mu_{L R}$ & $\mu_{R L}$ & $\mu_{T R}$ & $G_{T R}$ & $G_{L R}$ & $G_{R L}$ \\
\hline 7324 & 320 & 120 & 0.45 & 0.22 & 0.62 & 40 & 802.8 & 600.4 \\
\hline
\end{tabular}

Among them: $E_{L}, E_{R}$, and $E_{T}$ are the axial, chord, and radial elastic modulus, respectively; $\mu_{L R}, \mu_{R L}$, and $\mu_{T R}$ are the Poisson's ratio of the axial chord, axial chord, and radius chord, respectively; $G_{T R}, G_{L R}$, and $G_{R L}$ are the shearing modulus of the chord surface, the chord surface, and the chord of the shaft, respectively.

\subsection{Stubble Cutting Mechanism}

The exploration of the mechanism of Salix stump has a positive effect on the design and improvement of the double-action knife. The stubble mechanism is mainly reflected in two aspects: macro and micro. The detailed microscopic process is as follows:

First, the impact of the double-action knife edge Salix will bend, and elastic deformation of the fiber tensile stress will occur. Tensile stress exceeds the yield strength, the fiber fracture. Secondly, the blade will squeeze the bent stem fiber, making it continue to produce extrusion deformation, so that it becomes one end of the force, similar to the cantilever. Bending of the stalk fibers results in a relative misalignment between the individual fiber layers, resulting in shear damage [9]. At this time, the reciprocating double-acting knife needs to overcome the plastic deformation of Salix psammophila and the friction force between the saw blade and Salix. These results in cutting heat, some of which is transmitted to Salix psammophila, softening it and resulting in cutting force decline. In this process, the change of cutting force is not obvious, only occurring as small fluctuations [10]. Since the fibers are in a severed state with high tension, plastic deformation cannot yet be restored to its original state, and the crack in the bent fiber layer will gradually expand. Eventually, the stems are separated from the bottom of their roots for unsteady processes.

\section{Cutting Constitutive Model Establishment}

\subsection{Salix Constitutive Model Establishment}

Salix is a typical anisotropic material. In order to study the anisotropy of wood, Plays proposed the principle of orthogonal symmetry. In the mechanics of composites, the orthotropic material has three elastic principal axes, and the three elastic 
principal axes are all orthogonal to each other. The strain equation of the generalized Hooke's law of orthogonally symmetric materials is shown in Equation (1).

$$
\left\{\begin{array}{l}
\varepsilon_{L}=-E_{L}^{-1}\left(\sigma_{L}-\mu_{L R} \sigma_{R}-\mu_{L T} \sigma_{T}\right) \\
\varepsilon_{T}=-E_{T}^{-1}\left(\sigma_{T}-\mu_{T R} \sigma_{R}-\mu_{T L} \sigma_{L}\right) \\
\varepsilon_{R}=-E_{R}^{-1}\left(\sigma_{R}-\mu_{R L} \sigma_{L}-\mu_{R T} \sigma_{T}\right) \\
\gamma_{T R}=-\frac{\tau_{T R}}{G_{T R}} \\
\gamma_{R L}=-\frac{\tau_{R L}}{G_{R L}} \\
\gamma_{L T}=-\frac{\tau_{L T}}{G_{L T}}
\end{array}\right.
$$

Where $\varepsilon_{L}, \varepsilon_{R}$, and $\varepsilon_{T}$ denote the axial, chord wise, and radial line strain, respectively. $\sigma_{T}$ and $\sigma_{R}$ denote the radial, axial, and chord wise stresses, respectively. $\gamma_{T R}, \gamma_{L R}$, and $\gamma_{R L}$ denote the shear surface, axial chord, and axial chord shear strain, respectively.

According to the composite theory, there are three orthogonal elastic spindles in the orthotropic material, so the independent parameters of the stiffness matrix are reduced to nine. Equation (2) shows the Salix flexible matrix and rigid matrix, where $T, L, R$, are 1,2 and 3 , respectively.

$$
[C]=\left[\begin{array}{cccccc}
C_{11} & C_{12} & C_{13} & 0 & 0 & 0 \\
C_{21} & C_{22} & C_{23} & 0 & 0 & 0 \\
C_{31} & C_{32} & C_{33} & 0 & 0 & 0 \\
0 & 0 & 0 & C_{44} & 0 & 0 \\
0 & 0 & 0 & 0 & C_{55} & 0 \\
0 & 0 & 0 & 0 & 0 & C_{66}
\end{array}\right],[S]=\left[\begin{array}{cccccc}
S_{11} & S_{12} & S_{13} & 0 & 0 & 0 \\
S_{21} & S_{22} & S_{23} & 0 & 0 & 0 \\
S_{31} & S_{32} & S_{33} & 0 & 0 & 0 \\
0 & 0 & 0 & S_{44} & 0 & 0 \\
0 & 0 & 0 & 0 & S_{55} & 0 \\
0 & 0 & 0 & 0 & 0 & S_{66}
\end{array}\right]
$$

$C$ and $S$ are Engineering Elastic Constants. (3).

The elastic constants in the elastic matrix and the stiffness matrix can be expressed by GI and Eli, as shown in Equation

$$
[S]=\left[\begin{array}{cccccc}
\frac{1}{E_{L}} & -\frac{\mu_{R L}}{E_{L}} & -\frac{\mu_{R L}}{E_{L}} & 0 & 0 & 0 \\
-\frac{\mu_{R L}}{E_{L}} & -\frac{\mu_{R L}}{E_{L}} & -\frac{\mu_{R L}}{E_{L}} & 0 & 0 & 0 \\
-\frac{\mu_{T L}}{E_{L}} & -\frac{\mu_{R L}}{E_{L}} & -\frac{\mu_{R L}}{E_{L}} & 0 & 0 & 0 \\
0 & 0 & 0 & \frac{1}{G_{L R}} & 0 & 0 \\
0 & 0 & 0 & 0 & \frac{1}{G_{R T}} & 0 \\
0 & 0 & 0 & 0 & 0 & \frac{1}{G_{L R}}
\end{array}\right]
$$

The data obtained in Table 1 can be taken into Equation (3) to obtain the constitutive model of Salix psammophila. 


$$
[S]=\left[\begin{array}{cccccc}
\frac{1}{7324} & -\frac{0.22}{320} & -\frac{0.45}{120} & 0 & 0 & 0 \\
-\frac{0.22}{7324} & \frac{1}{320} & -\frac{0.62}{120} & 0 & 0 & 0 \\
-\frac{0.45}{7324} & -\frac{0.62}{320} & \frac{1}{120} & 0 & 0 & 0 \\
0 & 0 & 0 & \frac{1}{40} & 0 & 0 \\
0 & 0 & 0 & 0 & \frac{1}{600.4} & 0 \\
0 & 0 & 0 & 0 & 0 & \frac{1}{802.8}
\end{array}\right]
$$

\subsection{Double-Action Knife Constitutive Model Establishment}

The reciprocating double-action knife mainly includes knives, bolts, guard blades and other parts. The characteristics are as follows: knife angle of $19^{\circ}$, blade with $65 \mathrm{Mn}$, blade heat treatment, quenching with a hardness of HRC50-60, and nonquenching zone lower than HRC35.

The Salix lawn harvester double-action knife $65 \mathrm{Mn}$ is selected for the yield strength. The relevant parameters are listed in Table 2. A material safety factor of 1.5 is advisable.

\begin{tabular}{ccccc} 
& \multicolumn{3}{c}{ Table 2. 65Mn Material Parameter0 } & Tensile \\
\hline Material & $\begin{array}{c}\text { Young's } \\
\text { Modulus } \\
(\mathrm{MP})\end{array}$ & $\begin{array}{c}\text { Poisson's } \\
\text { Ratio }\end{array}$ & $\begin{array}{l}\text { Density } \\
\left(\mathrm{Kg} / \mathrm{m}^{2}\right)\end{array}$ & $\begin{array}{l}\text { Yength } \\
(\mathrm{MP})\end{array}$ \\
\hline $65 \mathrm{Mn}$ & $2.11 \times 105$ & 0.288 & 7.82 & 735 \\
$(\mathrm{MP})$
\end{tabular}

\section{Establishment of Geometrical Model of Sali Parallel Stubble}

\subsection{Double-Action Knife Geometric Model}

In order to simulate actual Salix stubble, it is necessary to establish a collection model that matches the real situation as closely as possible. At different ages, Salix has different heights and diameters. Three-year-old test material is used in this paper. The Salix sample collected has a diameter of $40 \mathrm{~mm}$ and height of $1000 \mathrm{~mm}$. The actual stubble cutting often uses reciprocating stubble GB1209 $1213 \sim 86$. The reciprocating double-action shrub Berger overall structure is shown in Figure 2 .

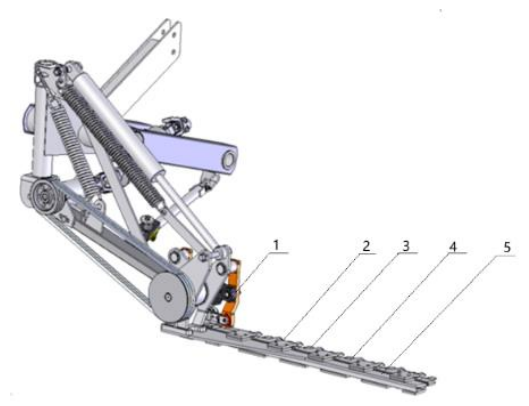

1. Flywheel; 2. Floating branches agencies; 3. Pressure edge (care blade); 4. On the knife; 5. Knife beam Figure 2. Reciprocating double-action shrub Berger overall structure

In order to improve the efficiency of stubble shrub stubble machine and adapt to the poor conditions of stubble in Northwest China, the reciprocating double-action shrub Berger shredder is installed in the following double-action knife. The reciprocating double-action shrub Berger double-edged knife is in the shape of a two-dimensional map, as shown in Figure 3. The double-acting knife cutter blade structure and installation of the main parameters are shown in Figure 4. 


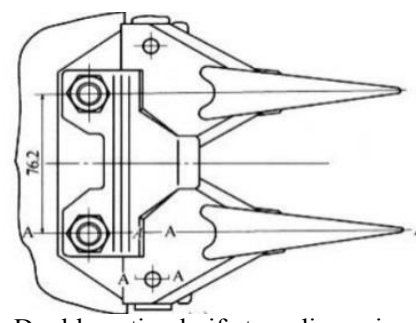

Figure 3. Double-action knife two-dimensional map
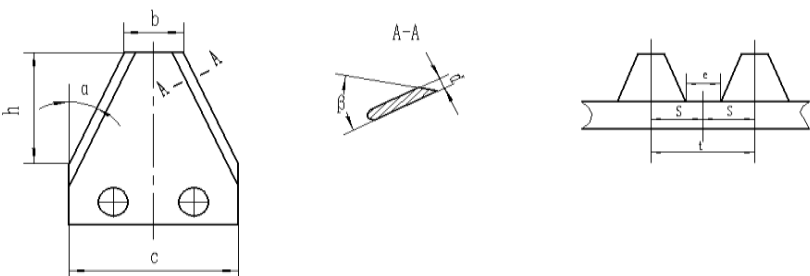

Figure 4. Double-acting knife cutter blade structure and installation of the main parameters diagram

The size relationship is $S=2 t=2 t^{\prime}=152.4 \mathrm{~mm}(6 \mathrm{in})$, the shape and size of which determine its ease of manufacture. The stubble is characterized in that the cutting stubble has higher stubble speed, stronger performance, larger inclination to coarse and thin stalks, better compatibility of cutting stubble, and is mainly applied to crops with smaller hardness.

In order to successfully finish the stubble simulation, we need to simplify the double-action knife properly. Therefore, the two mounting holes on the tool face in the simulation will be omitted. The Salix model and double-action knife model modeling in UG software are shown in Figure 5.

\subsection{Salix Geometry Model}

In the Salix geometry modeling process, perform the following simplification:

(1) Ignore the changes in the physical and chemical properties and the basic organization of Salix psammophila and the single cross sectional area. In the process of modeling Salix, Salix will be seen as a cylinder of equal section, without regard to Salix bending and so on.

(2) A single Salix will be used as the sawing object, regardless of the implicate effect between branches.

Based on the above two points, we construct a 3D model of Salix in UG as shown in Figure 6.

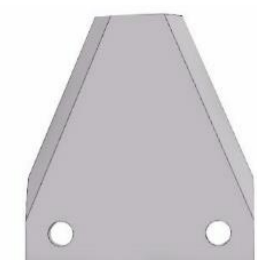

Figure 5. Double-action knife three-dimensional model diagram

Figure 6. Salix three-dimensional model 


\section{Finite Element Model Establishment}

\subsection{Meshing}

After the three-dimensional modeling of the Salix William double-action knife using UG is completed, the hexahedral mesh is divided by Hyper Mesh [11]. The number of Hex8 cells in the 3D mesh of double-action knife is 7789, the number of nodes is 10476 , the number of units is 7200 , and the number of nodes is 7736 . The grid type is Hex 8 , so the grid meets the requirements. In order to improve meshing and simulate the cutting efficiency, it is necessary to simplify the necessary tools. The Salix and double-action knife meshing results are shown in Figures 7 and 8.

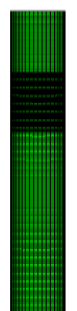

Figure 7. Salix meshing model

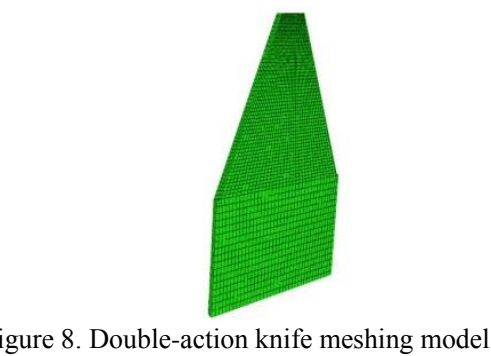

\subsection{Create a Cutting Model}

The cutting process of the double-action knife is a very complex non-linear process. Numerical simulation analysis using the finite element method requires some simplification of the cutting model to limit all the degrees of freedom of the Salix bottom node, that is, full constraint. Set the reciprocating degree of freedom in the X-axis direction and the freedom of feeding in the $\mathrm{Y}$-axis direction of the double-action knife. The double moving knife feed speed is $1.4-1.6 \mathrm{~m} / \mathrm{s}$, and the results are shown in Figure 9.

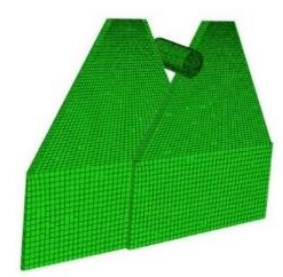

Figure 9. Salix simulation cutting diagram

After the cutting is finished, the result of cutting Salix is shown in Figure 10.

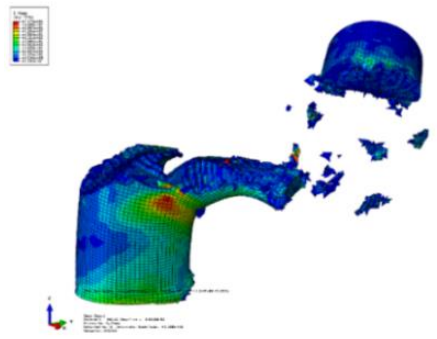

Figure 10. Salix cutting result diagram 
Figure 10 shows the torn Salix that has been cut, which will seriously affect the germination rate of Salix in the coming year. In the cutting process, the tool is not uniform and the vibration of the stubble is the main reason for this phenomenon.

\section{Double-Action Knife Topology Optimization}

\subsection{Double-Action Knife Vibration Analysis}

Requirements in a certain quality meet the conditions of the double-acting knife to perform reciprocating motion. The resulting reciprocating inertial force and some inherent imbalance centrifugal inertial force coupling make the machine produce a slight vibration. The double-action knife has uniform thin-walled parts, and the axial force will stimulate the double-action knife's own vibration. When the external excitation reaches the natural frequency of the double-action knife itself, the vibration will reach the maximum, that is, double-action knife resonance. This will not only cause very loud noise during the operation of the double-action knife, but also affect the stability of the double-action knife. The double-action knife vibration form is divided into two forms: horizontal vibration and radial vibration. Double-action knife transverse vibration refers to the double-acting knife axial reciprocating motion along the motor shaft. Radial vibration of the doubleacting knife occurs along its diameter direction due to stretching vibration.

In order to reduce the force of the contact point of the double-action knife and balance the force of the double-action knife to avoid the double-action knife resonance failure, topology optimization of the double-action knife is necessary.

\subsection{Topology Optimization of Reciprocating Bush Stubble Cutters}

The topology optimization principle is a set of mathematics, mechanics, and basic theory. Optimized mathematical models (objective functions, constraints, design variables) are proposed to optimize the structure under constraint conditions (egg, strength, stiffness, stability, etc.) [12]. OptiStruct software is Altair's proprietary software for topology optimization and is also a professional solver. OptiStruct relies on mathematical program sensitivity, standard objective functions, and constraint optimization algorithms [13]. The three elements of topology optimization of the double-action knife are as follows:

The objective function: the minimum vibration displacement peak.

Design variables: design space cell density.

Constraints: the volume fraction is limited to a range of 0.1 to 0.3 .

Use Hyper Mesh to load the user and create materials and properties, add constraints on the degree of freedom, and define topological optimization computational variables, volume objectives, and iterative steps to observe the optimization process. Based on the provisions of the design variable density, the maximum density (1.0) of the unit body is where the material is solid. The minimum density (0.0) of the continuum indicates the material is empty. After 62 steps of iteration optimization, the final result is shown in Figure 11. After optimization, the quality is reduced by $0.136 \mathrm{~kg}$ and the quality reduction rate is $21.7 \%$.

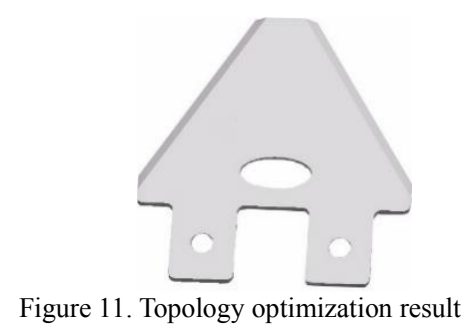

\subsection{After Optimization Verification}

After optimization, verify whether the topologically optimized blade significantly improves the stubble quality of the stubbler. Under the same cutting conditions, the simulation cutting is performed again. The result is shown in Figure 12.

Through the comparative analysis of Figures 10 and 12, the following conclusions are drawn: 
(1) Comparison of the cutting effect of Salix before and after the topological optimization can find that the degree of tearing of Salix psammophila is significantly reduced after topological optimization. This meets the stubble requirements.

(2) Comparison of the model of the double-action knife before and after topology optimization can find that the quality of the double-action knife is significantly reduced after topology optimization. The quality is reduced by $0.136 \mathrm{~kg}$ and the mass reduction rate is $21.7 \%$, which meets the requirement of reducing the quality.

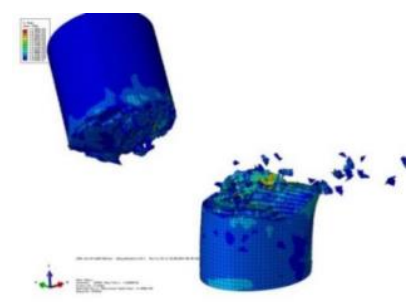

Figure 12. Optimized cutting results

After the simulated cutting is completed, the five nodes in one blade in the extraction double-action knife are 1367 , 1573, 2956, 3378, and 4559. The force is shown in Table 3. After optimization, the force conditions of the same node are extracted again, and the data of Table 4 is obtained under the same cutting conditions.

Table 3. Optimized tool force before the situation

\begin{tabular}{cccccc}
\hline Node & 1367 & 1573 & 2956 & 3378 & 4559 \\
\hline Force $(\mathrm{N})$ & 178.93 & 170.21 & 169.83 & 160.21 & 164.56 \\
\hline \multicolumn{6}{c}{ Table 4. Optimized tool force situation } \\
\hline Node & 1367 & 1573 & 2956 & 3378 & 4559 \\
\hline Force $(\mathrm{N})$ & 154.23 & 152.11 & 150.88 & 148.92 & 149.34 \\
\hline
\end{tabular}

Figure 13 characterizes the force line charts of Tables 3 and 4.

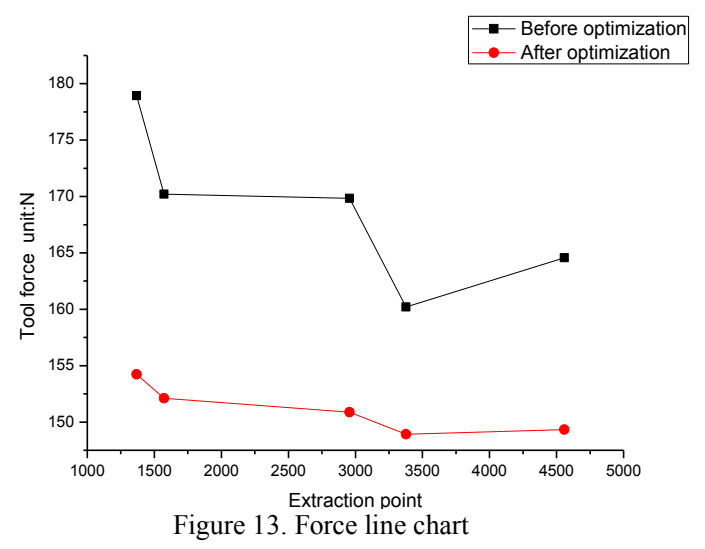

Figure 13 was analyzed:

(1) Node 1367 (double-action knife and Salix direct contact point) is the maximum force and thus the double-action knife and wood contact point of the most serious wear.

(2) The first five points of optimization of the force variance is 39.48 and the degree of dispersion is larger, indicating that the cutting process is not uniform. After optimization, five points of force variance 3.50 greatly reduced the degree of dispersion, and the line chart can intuitively understand the optimized tool force more evenly.

(3) Before optimization, the maximum stress of the tool is as high as $178.93 \mathrm{~N}$. If the local stress is too large, it will cause fatigue damage of the double-action knife, and the maximum stress point in the optimized tool will be reduced to 154.23N. The contrast shows topology optimization effectively solves the problem of local stress being too large, thereby reducing the fatigue damage stress points to ensure the life of the tool. 


\section{Optimization Design Tool of Reliability Theory Analysis}

\subsection{The Basic Mechanism}

The theory of reliability is based on a probabilistic approach to structural safety. It aims to assess the probability of failure of the structure: knowing the structure of a limit state criterion and the variability of the parameters involved, the probability of failure is defined as the probability that this criterion is exceeded [14].

Wear and tear on the performance of the double-acting knife can be used to measure wear and tear [15]. For abrasive wear, dual-action knife fracture toughness and hardness have a great impact on the wear resistance, and the wear rate $\mathrm{w}$ is calculated as follows:

$$
w=C \frac{1}{K_{I C}^{3 / 4} H^{1 / 2}}
$$

Where $K_{I C}^{3 / 4}$ is fracture toughness, $H$ is hardness, and $C$ is the coefficient of friction related factors.

Due to the comparative study of the reliability of the double-action knife before and after the research optimization, the effect of the work piece material on the double-action knife is not taken into consideration for the moment, so $C$ temporarily takes the constant. As improving the fracture toughness and hardness can improve the wear resistance of double-action knife material, the formula $K_{I C}^{3 / 4} H^{1 / 2}$ to some extent reflects the double-action knife wear resistance.

\subsection{Wear Life and Model}

Tool wear life is defined as the working conditions, to meet the specified blunt standard for the cutting time or cutting length [16]. The double-action knife blunt standard usually refers to the double-edged knife face average wear $\mathrm{M}$, as shown in Figure 14. Before and after optimization, the impact of Salix shrub materials is not considered. When the wear $M$ is determined, then the wear volume is also determined.

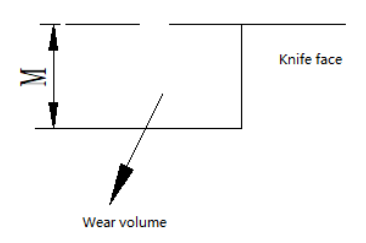

Figure 14. Double-acting edge wear

\subsection{Determination of Wear Life}

After blunt standard $M$ is determined, the wear volume $V$ is also determined. According to the Equation (5), the tool wear life $t$ is:

$$
\begin{gathered}
t=\frac{V}{w}=\frac{V K_{I C}^{3 / 4} H^{1 / 2}}{C}=C_{1} K_{I C}^{3 / 4} H^{1 / 2}=C_{1} B \\
B=K_{I C}^{3 / 4} H^{1 / 2}
\end{gathered}
$$

Where $C_{1}$ is the constant related to the cutting process. For the optimization before and after using the same cutting process, $C_{1}$ remains unchanged. Taking the logarithmic operation of both sides of Equation (6) yields:

$$
\begin{gathered}
\operatorname{Int}=\operatorname{In} C_{1}+\operatorname{InB}=\operatorname{InB}+C_{c o n} \\
C_{c o n}=\operatorname{In} C_{1}
\end{gathered}
$$


The cutting test method is used to determine the value of $C_{c o n}$. First, by determining the double-action knife blunt standard and then a set of cutting tests, you can obtain double-acting wear life t test values and the average $\bar{t}$. Secondly, measure $K_{I C}^{3 / 4}$ and $H$ using Equation (7) to obtain the average $\bar{B}$, and then:

$$
C_{c o n}=\operatorname{In} \bar{t}-\operatorname{In} \bar{B}
$$

The double-acting knife wear life is written as:

$$
\operatorname{Int}=C_{c o n}+\operatorname{InB}
$$

From Equation (10), it can be seen that the wear life at a certain moment during the double-action cutting process is related to the material mechanical properties of the double-action knife and the parameters in the cutting process [17]. Since the influence of the friction coefficient $C$ is neglected for the moment in the analysis of Equation (5), the friction of the double-action knife decreases after the double-action knife is optimized and the quality of the tool before optimization is reduced. Then, the optimization of dual-action life expectancy is better than before optimization.

\section{Optimized Tool for Reliability Verification}

\subsection{Fundamentals}

Wood is a natural biological material composed of plant cells, and it shows anisotropy in mechanics and physical properties. However, the performance of the cutting tool is dispersed. The cutting tool has randomness under actual sawing working conditions [18]. Therefore, there is a large randomness and dispersion for the double-action saw blade in the process of sawdust wear life and damage life. The optimized double-action knife has the characteristics of randomness and certain quantity. The method of probability and data statistics is used to quantitatively describe the reliability of the optimized double-action knife, with reliable life as a double-action knife reliability evaluation index [19].

The reliability of double-action knife $R(t)$ is related to the damage probability $F(t)$ under the specified time and sawing conditions:

$$
R(t)+F(t)=1
$$

The optimized double-action knife damage probability density is written as:

$$
f(t)=F^{\prime}(t)=1-R^{\prime}(T)
$$

The damage status of the double-action knife changes dynamically with working hours. Supposing the damage rate of one tooth in the double-action knife is $\lambda_{t}$, and the reliability of one tooth in the double-action knife is $R(t)=f(t) \cdot \lambda_{t}$. The damage rate of the tool is obtained by the tool under the specified conditions, and the quality of the tool wear reduces at a certain moment in the work process [20].

Reliability of Double-Action Knives Lifetime $t_{r}$ refers to the time of the sawing action when the double-action knife reaches the specified reliability $\mathrm{r}$, i.e., the tool life at $R(t r)=r$. The reliability of dual knife $R_{X}(t)$ is far lower than the reliability of one of the double-action knifes. The reliability of a blade of a double-action knife is the ability of the cutting quality of the mouth surface after the double-action knife cuts the stem stalk to meet the requirements under the specified conditions and working time.

$$
R_{X}(t)=[R(t)]^{X}
$$

Where $X$ denotes the knife number, and the above formula can be used to evaluate the reliability of the double-action knife.

\subsection{Calculation Example}

The test site is Zhunge'erqi, Ordos City and Inner Mongolia. The test site is flat and the surface soil is fine gravel. There is 
no gravel on the surface. Specimens selected were two- to three-year-old Salix shrubs, with Salix root diameters of $500 \sim 700 \mathrm{~mm}$ and Salix shrub root diameters of 5 60 mm. Two groups of cutting tests were carried out with ten eight-tooth double-action knives. There is one set of five optimized knives and another set containing five knives without optimization. There are two groups of Salix in the same area, with the same age. In the experiment, the moving speed of the double-action knife against the Salix shrub is $1.5 \mathrm{~m} / \mathrm{s}$, the cutting angle is the cutting way, and the influence of other factors on the doubleaction knife is minimized during the experiment. One double-action knife Saurong shrub cutting does the best job for the effect of cutting incision, and the cutting section is a relatively smooth oval or circle, as shown in Figure 15 . When the blunt volume of the double-acting cutter is calculated as shown in Figure 16, the blunt volume of the double-acting cutter is used as the criterion for the maximum life of the double-acting cutter.

At present, the most common theory in research and application is the weakest link theory [21]. The weakest link theory assumes that a member is made up of a series of volumetric units. The failure of a member is determined by the most dangerous volume unit, i.e., the failure of a member originates from the most unstable volume unit in the member. The double-action knife, which has a tooth, cannot meet the reliability requirements. When one of the teeth of the double-acting knife works as shown in Figure 16 when cutting a Salix bush, the maximum life of the tooth is considered, and then the double-acting knife cannot meet the reliability requirements. In the cutting process, the reliability of the double-acting cutter is judged according to the wear volume of the most severely worn teeth in the double-acting cutter. Figure 17 shows the relationship between cutting tool reliability and cutting time.

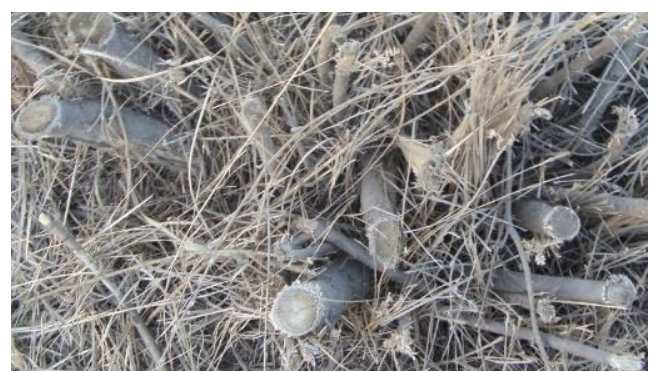

Figure 15. Double-action knife ideal cutting situation

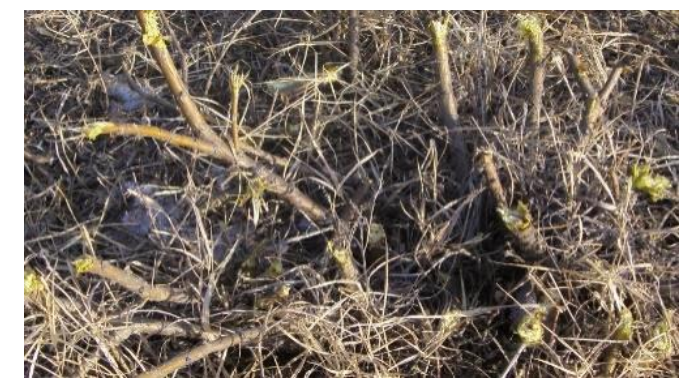

Figure 16. Double-action knife grinding blunt cutting conditions

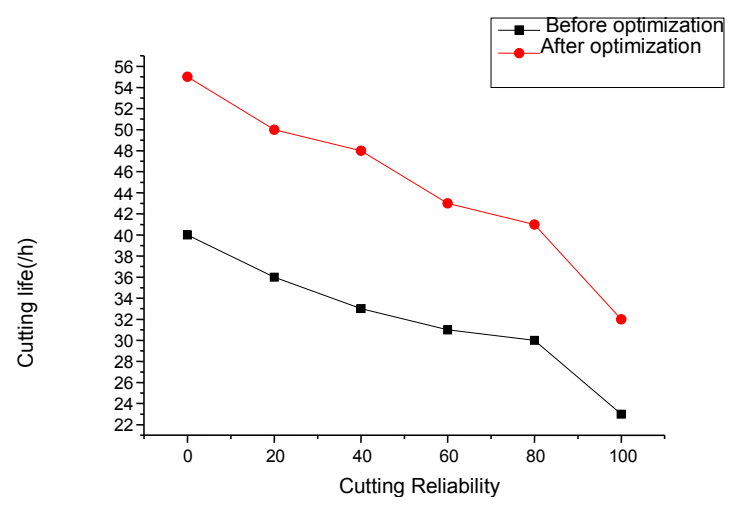

Figure 17. Relationship between cutting reliability and cutting time of double moving cutter

At the same time, random optimization has optimized the double knife two. Select the continuous three Salix psammophila as the test object, and record the total number of each Salix psammophila, number of stubble, number of 
missing cutting, number of re-cut, and number of stubble with heights greater than $50 \mathrm{~mm}$. The test results are shown in Tables 5 to 8 .

Table 5. The results of harvesting Salix psammophila of the first non-optimized double-acting shrubber harvester

\begin{tabular}{|c|c|c|c|c|c|c|c|c|c|}
\hline Numbering & $\begin{array}{c}\text { Plant } \\
\text { density } \\
\text { (plants } \\
\text { /from) }\end{array}$ & $\begin{array}{c}\text { Stubble } \\
\text { number } \\
\text { strain }\end{array}$ & $\begin{array}{c}\text { Breaking rate } \\
/ \%\end{array}$ & $\begin{array}{c}\text { Leakae } \\
\text { number } \\
\text { strain }\end{array}$ & $\begin{array}{c}\text { Leakage } \\
\text { rate } / \%\end{array}$ & $\begin{array}{l}\text { Weight/ } \\
\text { strain }\end{array}$ & $\begin{array}{l}\text { Heavy } \\
\text { cut } / \%\end{array}$ & $\begin{array}{c}\text { Stubble } \\
\text { height } \\
\geq 50 \mathrm{~mm} \\
\text { number }\end{array}$ & $\begin{array}{l}\text { Stubbs high } \\
\text { failure } \\
\text { rate } / \%\end{array}$ \\
\hline 1 & 51 & 2 & 5.9 & 3 & 5.9 & 1 & 2.0 & 4 & 7.8 \\
\hline 2 & 67 & 2 & 4.5 & 5 & 7.5 & 1 & 1.5 & 2 & 3.0 \\
\hline 3 & 74 & 4 & 5.4 & 3 & 4.1 & 2 & 2.7 & 3 & 4.1 \\
\hline Total & 192 & 8 & 4.2 & 11 & 5.7 & 4 & 2.1 & 9 & 4.7 \\
\hline
\end{tabular}

Table 6. The results of harvesting Salix psammophila of the second non-optimized double-action shrubber harvester

\begin{tabular}{|c|c|c|c|c|c|c|c|c|c|}
\hline Numbering & $\begin{array}{l}\text { Plant } \\
\text { density } \\
\text { (plants } \\
\text { /from) }\end{array}$ & $\begin{array}{l}\text { Stubble } \\
\text { number } \\
\text { strain }\end{array}$ & $\begin{array}{c}\text { Breaking rate } \\
\qquad / \%\end{array}$ & $\begin{array}{l}\text { Leakage } \\
\text { number } \\
\text { strain }\end{array}$ & $\begin{array}{l}\text { Leakage } \\
\text { rate/\% }\end{array}$ & $\begin{array}{l}\text { Weight/ } \\
\text { strain }\end{array}$ & $\begin{array}{l}\text { Heavy } \\
\text { cut } / \%\end{array}$ & $\begin{array}{l}\text { Stubble } \\
\text { height } \\
\geq 50 \mathrm{~mm} \\
\text { number }\end{array}$ & $\begin{array}{c}\text { Stubbs high } \\
\text { failure } \\
\text { rate } \%\end{array}$ \\
\hline 1 & 46 & 1 & 2.2 & 1 & 2.2 & 2 & 4.3 & 0 & 0 \\
\hline 2 & 75 & 3 & 4.0 & 2 & 2.7 & 1 & 1.3 & 1 & .3 \\
\hline 3 & 61 & 2 & 3.3 & 1 & 1.6 & 2 & 3.3 & 3 & 4.9 \\
\hline Total & 182 & 6 & 3.3 & 4 & 2.3 & 5 & 2.7 & 4 & 2.3 \\
\hline
\end{tabular}

Table 7. The results of harvesting Salix psammophila of the first optimized double-action shrub bush harvester

\begin{tabular}{|c|c|c|c|c|c|c|c|c|c|}
\hline Numbering & $\begin{array}{l}\text { Plant } \\
\text { density } \\
\text { (plants } \\
\text { /from) } \\
\end{array}$ & $\begin{array}{l}\text { Stubble } \\
\text { number } \\
\text { strain }\end{array}$ & $\begin{array}{c}\text { Breaking rate } \\
\qquad / \%\end{array}$ & $\begin{array}{c}\text { Leakage } \\
\text { number } \\
\text { strain }\end{array}$ & $\begin{array}{l}\text { Leakage } \\
\text { rate/\% }\end{array}$ & $\begin{array}{l}\text { Weight/ } \\
\text { strain }\end{array}$ & $\begin{array}{l}\text { Heavy } \\
\text { cut } / \%\end{array}$ & $\begin{array}{c}\text { Stubble } \\
\text { height } \\
\geq 50 \mathrm{~mm} \\
\text { number }\end{array}$ & $\begin{array}{c}\text { Stubbs high } \\
\text { failure } \\
\text { rate } \% \%\end{array}$ \\
\hline 1 & 56 & 3 & 5.4 & 1 & 1.7 & 3 & 5.3 & 0 & 0 \\
\hline 2 & 53 & 3 & 5.7 & 2 & 3.5 & 2 & 3.7 & 2 & 3.8 \\
\hline 3 & 76 & 4 & 5.3 & 0 & 0 & 2 & 2.6 & 0 & 0 \\
\hline Total & 185 & 10 & 5.4 & 3 & 1.6 & 7 & 3.8 & 2 & 1.1 \\
\hline
\end{tabular}

Table 8. Results of harvesting Salix psammophila with the second optimized double-action shrub harvester

\begin{tabular}{|c|c|c|c|c|c|c|c|c|c|}
\hline Numbering & $\begin{array}{c}\text { Plant } \\
\text { density } \\
\text { (plants } \\
\text { /from) }\end{array}$ & $\begin{array}{c}\text { Stubble } \\
\text { number } \\
\text { strain }\end{array}$ & $\begin{array}{l}\text { Breaking rate } \\
\qquad / \%\end{array}$ & $\begin{array}{c}\text { Leakage } \\
\text { number } \\
\text { strain }\end{array}$ & $\begin{array}{l}\text { Leakage } \\
\text { rate } / \%\end{array}$ & $\begin{array}{l}\text { Weight/ } \\
\text { strain }\end{array}$ & $\begin{array}{l}\text { Heavy } \\
\text { cut } / \%\end{array}$ & $\begin{array}{c}\text { Stubble } \\
\text { height } \\
\geq 50 \mathrm{~mm} \\
\text { number }\end{array}$ & $\begin{array}{l}\text { Stubbs high } \\
\text { failure } \\
\text { rate } / \%\end{array}$ \\
\hline 1 & 77 & 4 & 5.2 & 2 & 2.2 & 3 & 4.0 & 1 & 1.3 \\
\hline 2 & 72 & 3 & 1.4 & 2 & 2.7 & 3 & 4.2 & 2 & 2.3 \\
\hline 3 & 41 & 1 & 2.4 & 0 & 0 & 2 & 4.9 & 0 & 0 \\
\hline Total & 188 & 8 & 4.2 & 4 & 2.1 & 8 & 4.3 & 4 & 2.1 \\
\hline
\end{tabular}

In the process of stubble, the force that the tool is subjected to is the main index to evaluate the tool's performance, which has a direct impact on the working performance and service life of the tool [22]. It can be clearly seen from the figure that when the dual-action cutting tool has the same reliability, the optimized double-action tool life is longer. The results show that the optimized tool can meet the reliability requirements and prolong the cutting life.

Through comparative analysis of test results from Tables 5-8, it can be seen that the optimized double-action knife in the stubble rate was significantly higher than the double-knife without optimization. In the leakage rate, the stubble rate was lower than the unoptimized double-action knife. The results show that the reliability of the double-action knife after topology optimization is obviously improved.

\section{Conclusions}

(1) The finite element model of Salix cutting was established, and numerical simulation cutting was carried out. The stress of the relevant nodes in the cutting process was obtained. The results of simulation cutting show that: stubble force is extremely uneven, the maximum stress value is too high, and stubble quality is poor, which resulted in stubble in the stubble due to the uneven force during the process of vibration, causing fatigue damage and reducing the service life of stubble.

(2) By using the finite element analysis method and the topology optimization analysis method, the structure of the Salix lawn harvester is optimized. By comparing the stress of cutting tools before and after cutting, we can see the 
following: the optimized model performance is significantly improved, the cutting force by the tool is significantly reduced and meets the microseismic, lightweight design requirements, and it is more economical. After the topological optimization of the double-action knife compared to the previous mass to reduce $0.136 \mathrm{~kg}$, the stubble quality is significantly improved.

(3) Through the theoretical analysis of the tool reliability after optimization design, it is found that the reliability of the dual-action knife life after topological optimization is improved.

(4) Through the optimization of the designed tool test and the use of statistical methods to calculate the tool life and cutting reliability before and after optimization, and the reliability of the double-acting knives was determined. It was found that the topologically optimized double-acting knife has better reliability and a longer cutting life.

\section{References}

1. X. R. Peng and Y. K. Zhai, "Re-Discussion on the Rational Model of Topology Optimization for Continuum Structures," Chinese Journal of Solid Mechanics, Vol. 37, No. 2, pp. 181-191, 2016

2. Z. W. Song and Y. F. Yin, "Optimizing Design on Knife Section of Reciprocating Cutter Bars for Harvesting Cotton Stalk," Transactions of the Chinese Society' of Agricultural Engineering, Vol. 32, No. 6, pp. 42-49, 2016

3. S. P. Zhang, Z. M. Wang, and J. G. Yang, "Tool Reliability and Life Assessment for Machine Tools," Computer Integrated Manufacturing Systems, Vol. 21, No. 6, pp. 1579-1584, 2015

4. X. G. Wang, C. M. Lu, and B. Y. Wang, "Research on Dynamic Reliability and Failure Rate of Cemented Carbide Tools," Journal of Northeastern University (Natural Science), Vol. 36, No. 6, pp. 843-847, 2015

5. A. Maizia, A. Hocine, and H. Dehmous, "Development of a Reliability-Mechanical: Numerical Model of Mechanical Behavior of a Multilayer Composite Plate," Applied Mechanics, Behavior of Materials and Engineering Systems, Springer International Publishing, 2017

6. C. Chen and G. Yu, "Effect of Sliding Cutting Angle of Bush Reciprocating Cutter on Bus," Journal of Beijing Forestry University, Vol. 33, No. 2, pp. 115-119, 2011

7. S. Wang, B. Zhang and X. W. Li, "Research Status on Thick Stalk Crop Cutting Device and its Problems and Development Proposals," Journal of Agricultural Mechanization Research, Vol. 39, No. 8, pp. 263-268, 2017

8. Z. Dong, Q. Meng, and D. Lu, "Analysis and Experiment of Multi-Degree-of-Freedom Sisal Harvester based on Finite Element Method," Journal of Agricultural Mechanization Research, Vol. 40, No. 5, pp. 30-35, 2018

9. Z. B. Yin and F. Huang, "Multi-Scale Design Theory and Cutting Reliability of Ceramic Cutting Tools for High-speed Cutting," Journal of Mechanical Engineering, Vol. 52, No. 3, pp. 100, 2016

10. X. L. Guo, J. He, and Z. H. Qi, "Friction Characteristics of Soft and Hard Coating Tool Materials and Wood Composites," Scientia Silvae Sinicae, Vol. 53, No. 11, pp. 164-169, 2017

11. Z. G. Liu, "Design and Experian End Oneself-propelled Shrub Cutter," Transaction-ns of the Chinese Society for Agriculture-l Machinery, Vol. S1, 2010

12. Z. H. Song and F. Y. Tian, "Simulation and Experiment of Reciprocating Cutter Dynamics of Cotton Stalk under Noload," Transactions of the Chinese Society of Agricultural Engineering, Vol. 28, No. 16, pp. 17-22, 2012

13. C. H. Pei, T. Li, and Z. G. Liu, "Numerical Simulation and Working Parameter Optimization based on Finite Element Sand Cutting Process," Journal of Agricultural Mechanization Research, Vol. 39, No. 10, pp. 82-87, 2017

14. S. F. Zhang, Z. H. Song, and Y. F. Yan, "Development and Experiment of Measurement and Control System for Crop Straw Cutting Test Bench," Transactions of the Chinese Society of Agricultural Engineering, Vol. 29, No. S1, pp. 10-17, 2013

15. K. Salonitis and A. Kolios, "Reliability Assessment of Cutting Tool Life Based on Surrogate Approximation Methods," The International Journal of Advanced Manufacturing Technology, 2014

16. B. Chen, C. Zhu, W. Yan, Z. Wu, and L. Tao, “Tool Reliability Assessment based on Grey Neural Network Modeling," Modern Manufacturing Engineering, No. 3, pp. 106-111+76, 2017

17. L. Li and Q. L. Li, "Wood Cutting Machine Reliability Calculation of the Cutting Power," Journal of Beijing Forestry University, No. 4, pp. 94-98, 1995

18. C. M. Yang, Y. Lu, and Y. Ma, "The Theory and Experiment of Laser Cutting Wood by Second Pulse," Scientia Silvae Sinicae, Vol. 53, No. 9, pp. 151-156, 2017

19. X. D. Li, Z. Fang, and Z. D. Han, "Dynamic Simulation of Hob-Type Sweet Sorghum Cutter Based on Ansys/ls-dyna," Journal of Agricultural Science and Technology, Vol. 17, No. 3, pp. 70-76, 2015

20. K. Salonitis and A. Kolios, "Reliability Assessment of Cutting Tool Life based on Surrogate Approximation Methods," The International Journal of Advanced Manufacturing Technology, 2014

21. Z. M. Wang, L. N. Ren, and H. Y. Duan, "Reliability Evaluation of Machine Tool with Durability Obeying Three-Parameter Weibull Distribution under Variable Processing Conditions," Journal of Xi'an Jiaotong University, Vol. 52, No. 4, pp. 77-83, 2018

22. X. Cui, F. Jiao, and P. Ming, "Reliability Analysis of Ceramic Cutting Tools in Continuous and Interrupted Hard Turning," Ceramics International, Vol. 43, No. 13, 2017 